UCRL- -93555

DE86 002606

\title{
ACCELERATORS FOR HEAVY ION FUSION
}

R. 0 . Bangerter

This paper was prepared for subnitial to Proceedings of the Symposium on Lasers and Particle Beams for Fusion and Strategic Defense, Rochester, NY, April 17-19, 1985.

\section{October 1985}

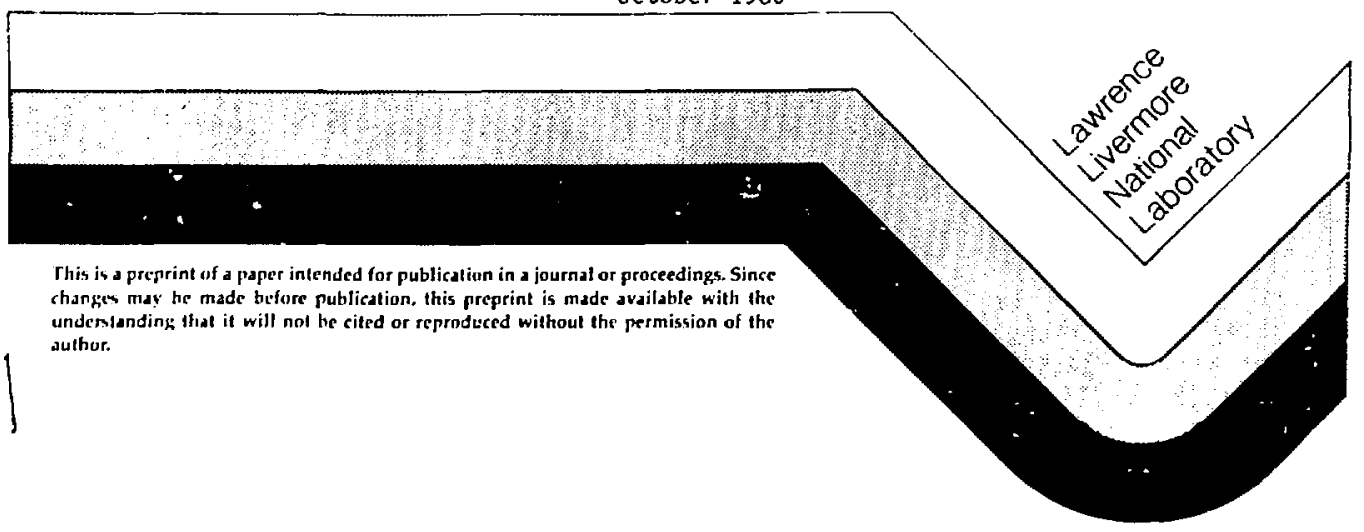


ACCELERATORS FOR HEAVY ION FUSION*

Roger Bangerter

Lamrence Livermore National Laboratory

Livermore, California

\section{Abstract}

Large fusion devices will almost certainly produce net energy. However, a successful comercial fusion energy system must also satisfy Important engineering and economic constrairits. Inertial confinement fusion power plants driven by mult-stage, heavy-ion accelerators appear capable of meeting these constraints. The reasons behind this promising outlook for heavy-ion fusion are given in this report. This report is based on the transcript of a talk presented at the Symposium on Lasers and Particle Beans for Fusion and Strategic Defense at the University of Rochester on April 17-19, 1985.

Work performed under the ausplces of the U. S. Department of Energy by the Lawrence LIvermore National Laboratory under contract nimber $W-7405-E N G-48$. 
I'm going to talk about accelerators for heavy-ion fusion, rather than accelerators for strategic defense systems. Consequently, I will first focus on generic fusion issues. I would like to begin by making an overstatement just to generate a little controversy. The overstatement is that engineering and economics are the important issues for fusion power pronuction. Nearly everyone belleves that many proposed fusion devices mould produce energy if they were made large enough. In fact, stars and nuclear weapons are two denonstrated examples. Large magnetic machines will also almost certainly produce net energy. On the other hand, these very large devices might not make good environmentel, englneering, or economic sense. So for commerctal applications of fusion, as opposed to mllitary applications, the important question is not whether fusion can produce energy, it is

Can a fusion energy system be bullt that makes good environmental, englneering, and economic sense?

A sensible fusion system must satisfy three conditions. The three requlrements are: (1) the total capitai cost of the system nust be acceptable; (2) the cost of electricity must also be acceptable; and finally (3) there must : a reasonable way to get from where we are today to where we want to be ultimately, 1.e., there must be a sensible Red path.

The three conditions are 1llustrated in Fig. 1. We do not know what the maximum allowable cost of a power plant will be in the future, but. if the economic situation is similar to the current situation, it is probably a few billion dollars. To be specific, a gool of less thar tmo billion dollars is indlcated in Fig. 1 . The cost of electricity, in 
order to be competitive, must be $\$ 50$ mills per kilowatt hour. This goel is also show in Fig. 1. A utopian goal of power plents that cost almost nothing and produce electricity for almost nothing is also shom. rur present position is illustrated by the region iabelled "now." we need to determine if there is a sensible path that leads from "now" to our goal. There are at least two difficulties or "swamps" that must be avoided. If we make the cost of our experinents too low, we typically have difficulty with physics. If we make the cost of our experiments too large, we have difficulty with economics.

I belleve that inertial confinement fusion (ICF) provides a reasonable RSD path. There are several reasons for this belief: one reason is that most orivers can grow because they are modular and they have reusable parts. A good example of this is the SHIVANOVETTE/NOVA sequence of lasers at Livermore. The fact that we can reuse some of the oriver components helps with the economics. On the other hand, the driver is not the whole issue. We will undoubtably find that reactor engineering will be challenging and expensive. It would be greatly advantageous if we could do reactor engineering at an inexpensive low level. In principle, ICF offers that possibility. Consider typical power plant parameters, a driver energy of 3 megajoules and a target gain of about 200 giving a thermonuclear yield of roughly 600 megajoules. If the repetition rate is five Hertz, the output is about 3,000 megaratis thermal. A power plant of this size vould be expensive. However, we could build a one-megejoule driver a lot more cheaply than a three-megajoule driver. Just as an example, it might be interesting to consider at test system that has a one-megajoule driver. The target gain drops somewhat compared to the gain et $3 \mathrm{~mJ}$. However, relatively simple targets might produce gains of $1-10$, giving themonuclear ylelds of 1-10 MJ. If we were to pulse et $10 \mathrm{Hertz}$, we would get 100 megamatts of thermal power. This power level would be sufficient to do many 
interesting react or englneering and testing projects. The advantage of such a system is that this smil yield of a fer megajoules could probably be contained in a sinall reactor chamber with dimensions of the order of a meter. Such a chember would be relatively inexpensive because it is not very blg. Furthermore, wo wight be able to make such a system tritium-self-surficient. In order to be tritium-self-sufficient, we must capture most of the neutrons that are produced in the thermonuclear bum and that means we must surround most of the solld angle around the reactor with tritlum breeding blankets. It should not be too expensive to surrouad a small reactor with tritlum-breeding blankets. On the other hand, If we try to start with very large systems, perhaps five meters or so in size, then, in fact, we do have formidable problems for reactor R\&D and tritlum self-sufficlency. In summary, the example given above shors that ICF may provide a reasonable ReD path.

I would now ilke to turn from generic fusion issues to heavy-ion fusion. The first question is "Why are we interested in heavy-ions as opposed to other lons?" One answer to this question is based on the range-energy relations. Figure 2 shows the range, in grans per square centimeter, as a function of ion energy in Gev. For ICF targets, we wruld like to have an ion range that is less than a fer tenths of a gram per square centimeter. Flgure 2 shows that if we want to use electrons or light ions, we are constrained to energies of a few MeV. On the cther hand, by going to very heavy-ions, we can consider extremely energetic lons, up to $10 \mathrm{GeV}$ or perhaps somewhat higher. Thus, for heavy-ions, we would use hlgh-voltage, low-current beans. These beans can be accelerated in a low-charge state, minimizing collective effects. Perhaps most importantly conventional accelerator technology then becomes applicable. What I mean by conventional accelerators is multi-stage accelerators. These conventional/mult1-stage accelerators are well matcied to the engineering requirements of fusion porer production. 
Accelerators are reliable; they typically operate more than $90 \mathrm{x}$ of scheduied time. They have a long lifetime; the large accelerators built in the '50's are still operating. They on have a high-pulse repetition rate, and of particular importance, they can be efficient (probably 15 to 35x for a heavy-ion acselerator). However, not all accelerators have demonstrated adequate lifetime for a fusion power plant. A fusion power plant, If it operates at 10 Hertz over a llfetime of 30 years, would have to pulse about $20^{10}$ times. That is a large number of pulses. The RF linac at SLAC, I suspect, has pulsed more than any other existing accelerator. I calculate that it has pulsed about $10^{11}$ times! Therefore, this type of technology certalniy seems capable of meeting the requirements of a poxer plant. The Astron injector, as far as induction linacs are concerned, is probably the record holder for number of puises. The Astron machine was pulsed about $10^{8}$ times. However, the components that go into modem Induction linacs should last for more than $10^{B}$ pulses. New types of capacitors are advertised to have 11 fetimes in ex.siss of $10^{9}$ pulses. Thyratrons, for switching at 10 pulses per second, should last about 10,000 hours, or about $a$ year. Therefore with a maintenance program for replacing some components, we should be able to build an induction linac that would also meet the requirement of $10^{10}$ pulses.

Despite my original emphasis of engineering and economics, the accolerator must, of course, also meet the scientific requirements for fusion. The abllity of accelerators and focusing systems to meet target requirements depends strongly on particle mass. Target performance depends on four parameters: (1) the focal radius of the beam; (2) the ion range, which depends on lon kinetic energy and mass; (3) the power; and (4) the beam enpigy. How easy is it to meet the target requirements? First consider beam brightness, or phase-space density. The target requirements and the properties of the focusing systems place 
a lower 1 imit on six-dimensionsi (6-D) phase-space density. Liouvilile's theorem as it is conventionally applied to accelerators, states that the 6-D phase-space density at the target, has to be less than or equal io the 6-D phase-space density at the ion source. There are some schemes that violate Llouville's theorem but most of them do not seem to be appilcatle to fusion.

It can be shown that the 6-D phase-space density needed at the target divided by the 6-D phase-space density avallable at the fon source goes as $M^{2} / \theta^{2}$ where $M$ is ion mass and $\theta^{2}$ is a measure of the solid ungle occupled by the bean (or beans) converging onto the target. If the target gain is held constant by fixing bean radius, Ion range, bean power, and bean energy, then $\varepsilon \leq-3$. The exact value of $\varepsilon$ depends on the assumptions that are made, but in any case heavy-ions can meet the requirement of Liouville's theorem more easily than light lons.

Another Important consideration is the strength of space charge forces relative to beam stiffness. Quantitatively, the important paraneter is generalized perveance, $K \propto I_{0} Z^{2}(1-f) /\left(M v^{3}\right)$, where $I_{0}$ is particle current, $Z$ is lon charge state, $f$ is fractional neutralization by electrons, and $v$ is velocity. Again fixing target performance, It can be shown that $K$ goes as $(1-f) M^{C}$ where $-2.5 \leq \theta \leq-0.5$. The exact value of $c$ depends on the charge state of the lons.

Another important paraneter is the beam plasma frequency

$$
{ }^{\omega} \mathrm{pb}=\left(\frac{4 x \cdot e^{2} z^{2}}{M}\right)^{1 / 2}
$$

where $e$ is the electron charge.

Beams with pigher $\omega_{p b}$ are more susceptible to various instabilitles than beams with loxer $\omega_{\mathrm{pb}}$. For fixed target paraneters $\omega_{p b}<M^{c}$ where $-1.2 \leq c \leq-0.2$. 
The design constraints associated with Liouville's theorem, Deneralized perveance, and beam plasma frequency are not easily satisfied. In order to use conventional accelerator techology, and in order to satisfy these constraints, we are pushed in tre direction of heavier ions.

Based on the considerations described abave, it appears that heavy-ion accelerators are reasonable in terms of petting us to our final goal of power production. Homever, it has been a little bit difficult to come up with a reasonable accelerator Red path. I would like to outline briefly the R\&D path in the United States. In the U.S. we have chosen to develop multiple-beam induction linacs. Figure 3 shows schematic diagrams of two types of fusion accelerators, a multiple-beam induction linac end an r.f. linac and storage ring system. An induction linac is a simple high-current device. The r.f. system is more complicated. In the r.f. system, ions from a number of lon sources (only four are shown) are funneled together to provide the beam for the main accelerator. However, the current in the main accelerator is not adequate to orive the target and therefore it is necessary to stack the beam into a series of storage IIngs in order to get edequate power for the target. The simplicity of the induction linac is important, because the beam manipulations such as funneling and stacking almost inevitably increase the 6-D phase-space volume occupled by the bean and, as stated earlier, a ss.111 6-D phase-space volume is needed to meet the target requirements.

There are other reasons for the choice of induction linacs in this country. Induction linacs can have high pulse repetition rates. The ATA induction machine at Livermore ${ }^{l}$ is designed for operation at $1 \mathrm{kHz}$. Furthermore, ATA and other similar accelerators have given us considerable experience with kiloampere electron induction linacs. A target requires $-10^{14}$ watts. Therefore, for $10 \mathrm{GeV}$ heavy-ions, the $20 \mathrm{KA}$ beem current demonstrated at ATA gives the required $10^{14}$ watts. 
The experience with induction linacs is inportant. Because of this experience we have alreaty developed the circuitry, the pulsers and the induction cores necessary to handle the currents required for ton bean fusion, but unfortinately the beams that we are now putting through these machines are electrons. The basic acceleration clrcultry does not know the difference between electrons and lons. It only knows about current. on the other hand, electrons are relativistic and lons are non-relet1vistic, and there are enomous differences in beam dynamics. Therefore, the really important question for heavy-ion fusion is:

Can we confine, accelerate, transport and focus the high beam current without destroying the beam quality?

The beam quality is good enough at the beginning of the accelerator; a typlcal ion source temperature might be $\sim \mathrm{leV}$. At a final energy of 10 $\mathrm{GeV}$, the transverse energy is 10 orders of magnitude below the directed energy, which means that the intrinsic beam divergence is $-10^{-5}$ radians however $10^{-3}$ radians is nearly adequate for fusion. Unfortunately there are a number of possible sources of trouble. There are non-1inear space-charged forces or magnetic forces associated with the beams; there are also potential Instabilities, multiple beam interaction effects, and imperfections in the machine. Incidentally, efficiency is rot a separate 1ssue. The efficiency of an induction linac can be good if the current is high. The circuitry designed for accelerating electrons appears capable of providing efficiencies as high os $50 \%$. Usually, the currents ossociated with lor accelerators are lower than the currents assoclated with electron machines, and that is the reason why th: 2 efflciency is not $50 \%$, but perhaps 15 to $35 \%$.

In general particle in an accelerator does not move directly along the axis of the accelerator in elther position or angle. As a 
consequence it is necessary to provide focusing forces to keep the particles in the machine. These focusing forces then ceuse the particles In the machine to undergo oscillations called betatron oscillations around the central orb1t. As one adds space charge, the space charge forces of the beam tend to counteract the applied focusing forces. As a consequence, both the amplitude and the wavelength of the betatron osclllations increase. If the space charge is increased to the point that the bean plasma frequency is close to the single-particle betation frequency, it is possible to accelerate very high currents, and improve both the cost and the efficlency of an induction linac. Unfortunately, analytic theory shows instabilities as the beam plasma frequency approaches the single-particle betatron frequency. The analytic theory Is based on idealized particle distribution functions. Numerical simulations wich use more realistic particle distribution functior; do not necessarily show these instabilities. At any rate, it is necessary to perform experiments, and a number of experiments have been performed, the largest at Laxrence Berkeley Laboratory. 2

The results of the experiments are in agreement with the numerical simulations and show that the analytically predicted instabilities are not observed. In fact, it has been posslble to transport beans at very high space-charged densities without observable degradation of beam quality. We now belleve that we can transport currents that are three or more times larger than thought possible several years ago.

The experiments that have been performed have tested only transverse beam dynanics. Lawrence Berkeley Laboratory is now building a so called MEE-4 accelerator which is a multiple beam experiment with four beams. The MBE-4 will enable us to study longitudinal beam dynamics and multiple beam Interactions.

Incidently, one place were there could be some overlap between the heavy-ion fusion program and SDI is in this area of multiple beams. SDI would like very brlght beans and also high currents. These same characteristics have led us to consider multiple beams for fusion. 
Cost has traditionally been an issue for heavy-ion fusion accelerators. We believe this issue can be resolved. Less expensive materlals are being developed for Induction cores, insulators, and magnetlc focusing magnets. Much of this progress is being driven by programs other than heavy-ion fusion. Fabrication techniques can also be impraved. Beam neutralization and control by electrons is being studied theoretically and experimentally and could give cost beneifits. Progress in fast repetitive switching tectinology at Livermort could open the possibility of new types of inexpensive induction accelerators. Finally, we belleve that improved target designs are possible.

In conclusion, heavy-ion fuston is a promising fusion option. ICF provides a sensible, economical reactor development path; and multi-stage accelerators are capable of satisfying the engineering requirements of fusion power production. Mulil-stage, heavy-ion acceierators also appear capable of satisfying the ICF target requirements. High efficiency is very important because it gives some margin of safety if the targets don't rork as well as we hape. We have developed a logical accelerator Rad path; and the experiments that we have performed sis far have been encouraging. Finally, cost reductions seem likely. 


\section{REFERENCES}

1. Reginato, L., "The Advanced Test Accelerator (ATA), A SOHeV, 10-kA Induction Linac", 1983 Particle Acceleration Conference, IEEE Transactions on Muclear Science, NS-30 4 (1983) 2970.

2. Chupp, w. et al., "A High Current Heavy Ion Beam Transport Experiment. at LBL", Lawrence Berkeley Laboratory Report LBL-17256. Also published in the Proceedings of the 1984 INS International Symposium? on Heavy Ion Accelerators and Their Applications to Inertial Fusion, Institute for Nuclear Study, University of Tokyo. Tokyo, Japan (1964), P. 460, Y. Hirao, T. Katayama, N. Tokuda editors. 


\section{Fiqure Captions}

Floure 1: A reasonable goal for fusion energy production in terms of cost of plent and cost of electricity is indicated above. Our curcent position is also indicated. A sensible fusion energy progran shculd take us from where we are now to our goal on a path that avolds the alligators lurking in the swamps on the left and on the right.

Flqure 2: Range as a function of lon kinetic energy for $P$ variety of charged particles. For inertial fusion, the range should be less than a few tenths of a gram per sguare centimeter. For heavy-ions, the kinetic energy can be $\leq 20 \mathrm{GeV}$. The curves in this figure are based on aluminum target material at a density and temperature typical of Inerilal fusion.

Figure 3: Schematic diagram of an induction linac and an r.f. linac plus stcrage rings. These systems are the two principal approaches to heayy-iori fusion. 


\section{Avoid alligators}

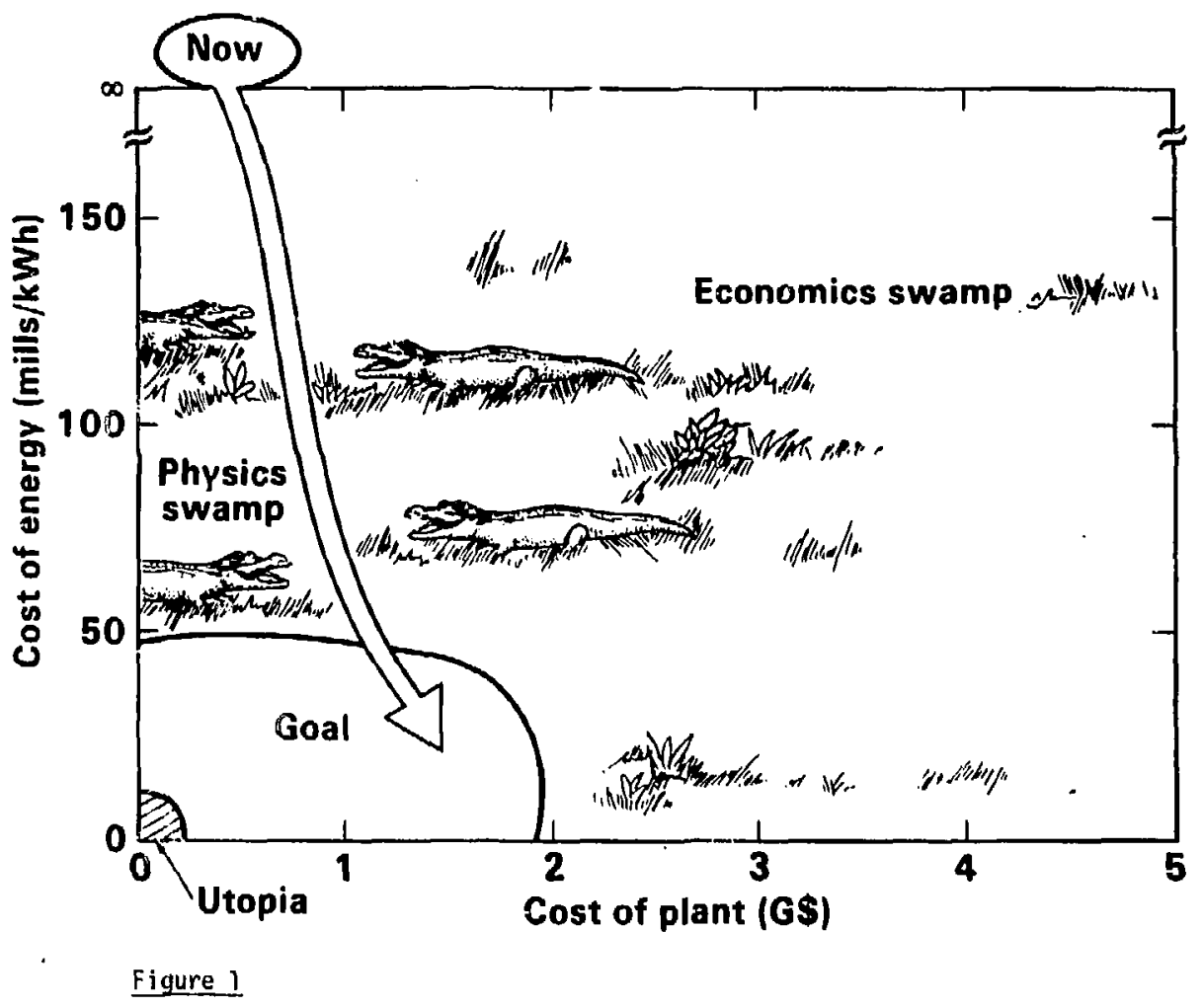


Heavy ions allow the use of high voltage, low current beams

- Acceleration can occur in a low charge state

- Collective effects are minimized

- Converitional acceleration technology is applicable

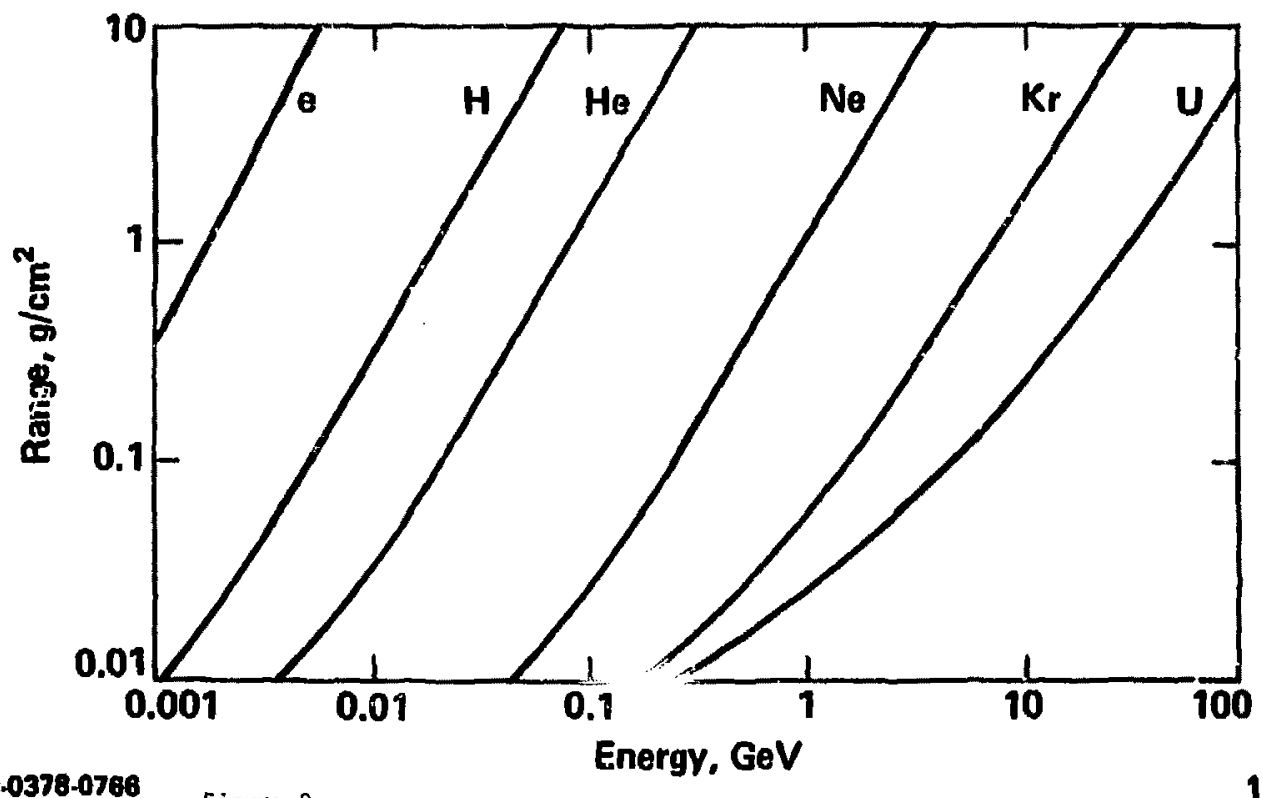

6060.0378-0768

Figure 2 


\section{The U.S. Program has chosen to develop muitiple-beam induction linacs}

- Induction linacs are conceptually simple

Induction linac

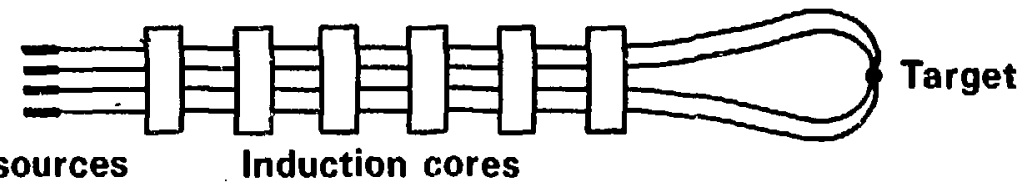

r.f. linac and storage rings

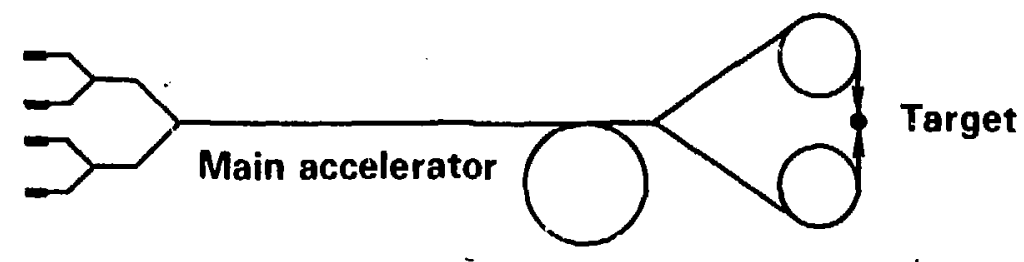

- Simplicity is important. Beam manipulations almost inevitably increase the 6-D phase-space volume occupied by the beam. A small focus requires a small 6-D phase-space volume.

Figure 3 


\section{DISCLAIMER}

This report was prepared as an account of work sponsored by an agency of the United States Governmenl. Neitl.sr the Urited Slates Government nor any agency thereof, nor any of their employees, makes any warradty, express or implied, or assumes any legal liability of tesponsibility for the accuracy, completeness, or usefulness of any information, apparatus, product, of prociss disclosed, or represents that its use would not infringe privately owned rights. Reference herein to any specific commercial product, process, of service hy irade name, Irademark, masufacture:, or otherwise does not necessarily constitute or imply its esdorsemert, recommendation, or favoring by the United States Government or any agency thereof. The views and opinions of authors expressed berein do not necessarily state of reflect those of the Uniled Si ates Government or any agency tbereof. 